\title{
Spatial inequality of dental caries in the Brazilian territory
}

\section{Rayanne Karina Silva CRUZ(a) Yan Nogueira Leite de FREITAS ${ }^{(b)}$ (i) Tamires Carneiro de Oliveira MENDES(a) \\ Janmille Valdivino da SILVA(a) Flávia Christiane de Azevedo MACHADO(a) (1) Maisa Paulino RODRIGUES(a) Maria Angela Fernandes FERREIRA ${ }^{(a)}$}

(a) Universidade Federal do Rio Grande do Norte - UFRN, Department of Dentistry, Natal, RN, Brazil.

(b) Universidade Federal do Amazonas - UFAM, Faculty of Dentistry, Manaus, AM, Brazil.
Corresponding Author:

Tamires Carneiro de Oliveira Mendes E-mail: tamires.carneiro@hotmail.com

https://doi.org/10.1590/1807-3107bor-2019.vol33.0122

Submitted: October 4, 2018

Accepted for publication: November 1, 2019

Last revision: November 29, 2019
Abstract: The distribution of harms to health varies spatially determined by the socioeconomic conditions of the environment. This research aimed to assess the spatial distribution of dental caries in 12-year-old children and their correlation with socioeconomic indicators in Brazilian states. The sample of this ecological study comprised all the 26 Brazilian states and the Federal District. Thematic and correlation maps were constructed in order to assess the spatial dependency, as well as the correlation between dental caries and socioeconomic factors. The results showed that the states with the worst DMFT indexes were located in the north and northeast, showing spatial autocorrelation. These regions also had the worst results for the following variables: poverty, illiteracy, education, and income. The bivariate analysis showed that household income and education level had negative spatial correlation with the DMFT index, while illiteracy and poverty rates showed positive correlation. Despite advances in the decline of DMFT index in recent years, there is still an inequity in the distribution of the caries disease.

Keywords: DMF Index; Socioeconomic Factors; Spatial Analysis.

\section{Introduction}

Health has been understood as the result of the social organization of production, which is affected by multiple factors, such as housing, food, education, work, income, environment, and access to goods and essential services, among others. ${ }^{1}$ According to the Organic Law of Health, ${ }^{2}$ health levels of the Brazilian population express the social and economic organization of the country. Oral health - as an integral part of health as a whole - is also included in this context and it is influenced by the same factors, in particular by the socioeconomic conditions of the population.

Brazil has a historical and large social inequity since its colonization to the present day. According to the Institute of Applied Economic Research (IPEA), the 20\% of families with the highest incomes in 2014 were 16 times more than the $20 \%$ of those families with the lowest incomes. In 2009, the Gini index of the country was 0.623 and in 2014 this number dropped to 0.518 . However, it should be recognized that serious disparities still persist. ${ }^{3,4}$

The Brazilian epidemiological framework with regard to oral health has confirmed this fact. In addition, in Brazil the use and access to oral health services are lower in the poorer regions. The literature has shown that the prevalence of low access to dental services varies widely between Brazilian 
capitals. In less developed regions, this prevalence is five times higher than the most developed regions as in South and Southeast capitals, for example. ${ }^{5,6}$ Socioeconomic inequality is a significant attribute of the Brazilian reality. It influences the health condition of the population and produces large implications for oral health, such as dental caries, toothache, and loss of teeth.?

The harms in oral health and their sequels are prevalent in Brazil, especially in the northeast states, which have major socioeconomic problems that reflect in the public health and have great political and social consequences. ${ }^{5,6,7}$ Thus, in recent years, the government has used epidemiological data to guide oral health public policies through national oral health surveys, such as those carried out in 2003 and 2010, known as the SBBrasil project. ${ }^{8}$

In addition to obtaining the primary data of dental morbidity, it is essential to assess and understand the distribution of these diseases within the territory and how they are linked to social and economic conditions of the population in order to effectively promote oral health. Health promotion is a complex task that involves the understanding of the relationship between the people and the patterns of development, sociocultural environment, needs, rights, and living conditions. ${ }^{8}$

Based on the above information, this study proposed to assess the spatial distribution of decayed, missing, and filled teeth (DMFT) in children with 12 years of age in the Brazilian federal states and the correlation with socioeconomic conditions in 2010.

\section{Methodology}

This was an ecological study with spatial aggregates, using the 26 Brazilian states and the Federal District as analysis unit. Oral health data were obtained from the 2010 SBBrsil Project carried out by the Ministry of Health.

Data on socioeconomic conditions of the Brazilian population, with reference to level of education, illiteracy rate, and unemployment rate, were obtained from PNAD 2009 (National Survey per Household Sample), while the Gini index, poverty rate, and household per capita income were obtained from IPEA
2009 (Institute of Applied Economic Research). The cartographic data in shapefile format from the Brazilian states and the Federal District were obtained from the Brazilian Institute of Geography and Statistics (IBGE).

As the 2010 SBBrasil Project only provides the DMFT of the capitals and the countryside of the region in which the state is located, we carried out a weighted calculation to obtain the DMFT of each state by the following formula:

DMFT of the state $=\frac{\text { Capital DMFT }+ \text { countryside DMFT }}{\text { Total state population }}$

The data were geo-referenced using the Terraview 4.1.0 software. In order to identify patterns in the spatial distribution of the DMFT, level of education, illiteracy rate, Gini index, poverty rate, household per capita income, and unemployment rate, we held exploratory analysis through visual inspection of thematic maps constructed with the use of the same software. The darker the shade on the maps the more unfavorable the outcome.

To assess the spatial autocorrelation of variables, we calculated Moran's I index for each variable. The index provides a general measure of the spatial association in a set of data and its value ranges from -1 to +1 , where values closer to -1 or +1 indicate high autocorrelation and values close to zero indicate low autocorrelation.

Subsequently, we assessed the presence of clusters through the Moran's I local indicators of spatial association (LISA), which estimates how similar or different are neighbors with common edges in the polygons, thus allowing to identify the spatial concentration of high and low values of indicators. The relationship between DMFT and socioeconomic conditions was evaluated by means of bivariate correlation, bivariate Moran's I index associated with visual inspection of dispersion charts, and thematic maps, made by the GeoDa 0.9.5 software.

\section{Results}

The DMFT in 12-year-olds ranged from 1.44 to 3.79 among states. In 2010, the DMFT distribution in the Brazilian states showed higher rates (3.12 to 3.79) concentrated in the northern and northeastern regions (Figure 1). 


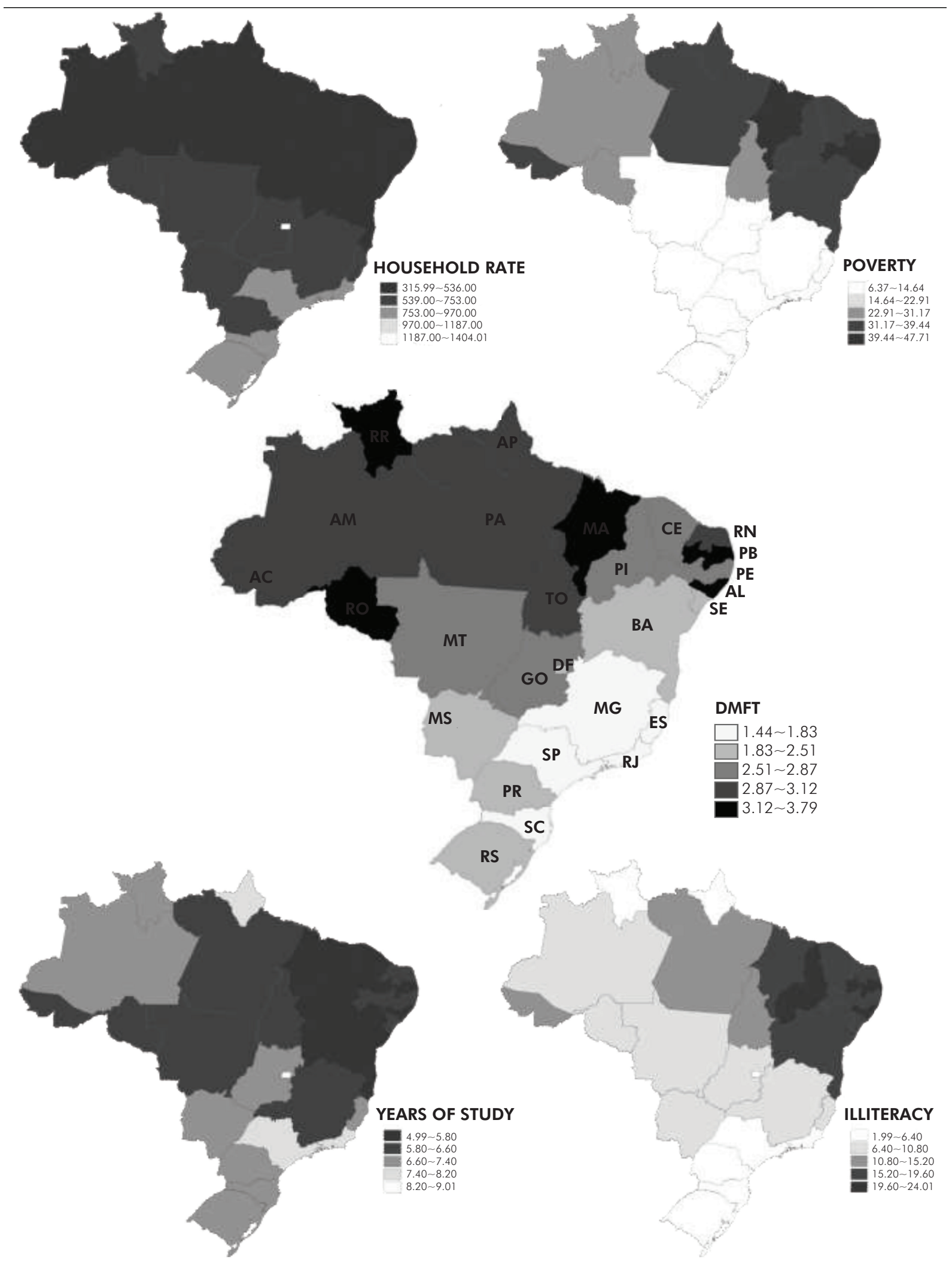

Figure 1. Exploratory spatial distribution map of DMFT in 12-year-olds (Center) among Brazilian states in 2010 and spatial distribution of the variables household per capita income, poverty rate, schooling, and illiteracy rate. 
The lowest household per capita incomes $(<536.00$ Brazilian reals) as well as the worst poverty rates (> 39.44\%) were concentrated in the states of the northern and northeastern regions. The highest levels of schooling ( $>7.4$ years of study) were in the south and southeast regions and part of the mid-west region. Some states in the northern region also showed high schooling levels. With regard to illiteracy, the worst rates $(>15.20 \%)$ were in the northeast states and the best rates $(<6.4 \%)$ in the southern states of the country. The unemployment rate and the Gini index showed a random spatial distribution.

Moran's I index showed a significant spatial autocorrelation of DMFT with household per capita income, schooling, illiteracy, and poverty and it was not statistically significant for unemployment rate and Gini index, corroborating with what had been observed in the exploratory thematic maps (Table).

The Brazilian states that had the lowest DMFT southern and southeastern regions - were also those that formed spatial clusters with higher household income and schooling rate (Figure 2). These data were opposed to the worst poverty and illiteracy rates that were spatially clustered in the states of the northern and northeastern regions, which had the highest DMFT indexes (Figure 3).

In the bivariate analysis, household per capita income showed a negative spatial correlation with DMFT, thus confirming that the increase in household

Table. Spatial autocorrelation of the study variables.

\begin{tabular}{lcc}
\hline Variable & Moran's I Index & p-value \\
\hline DMFT in 12-year-olds & 0.30 & 0.03 \\
Household per capita income & 0.18 & 0.04 \\
Unemployment rate & 0.14 & 0.20 \\
Schooling rate & 0.17 & 0.05 \\
Illiteracy rate & 0.29 & 0.02 \\
Poverty rate & 0.33 & 0.01 \\
Gini index & 0.0006 & 0.58 \\
\hline
\end{tabular}
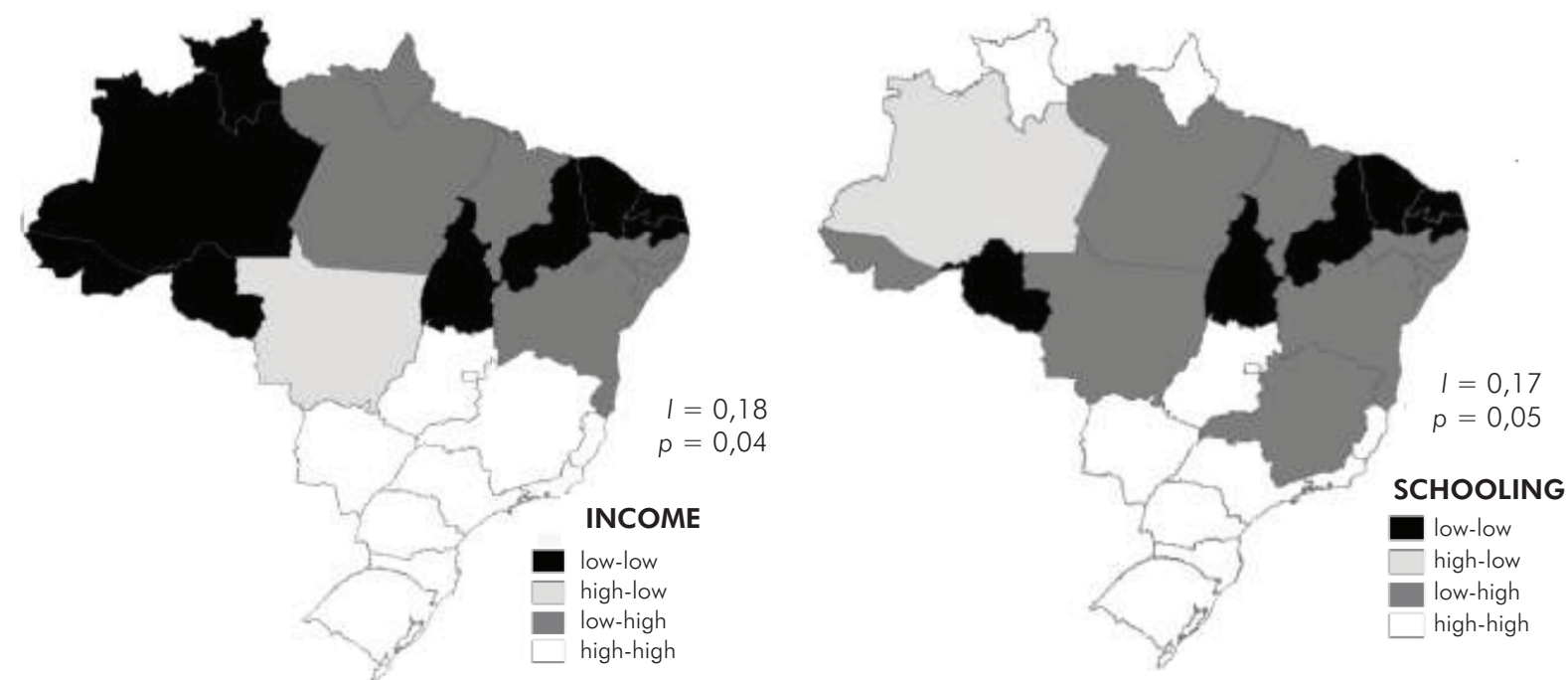

Figure 2. Box map of spatial distribution of Brazilian socioeconomic conditions showing household per capita income and level of education in 2009. 


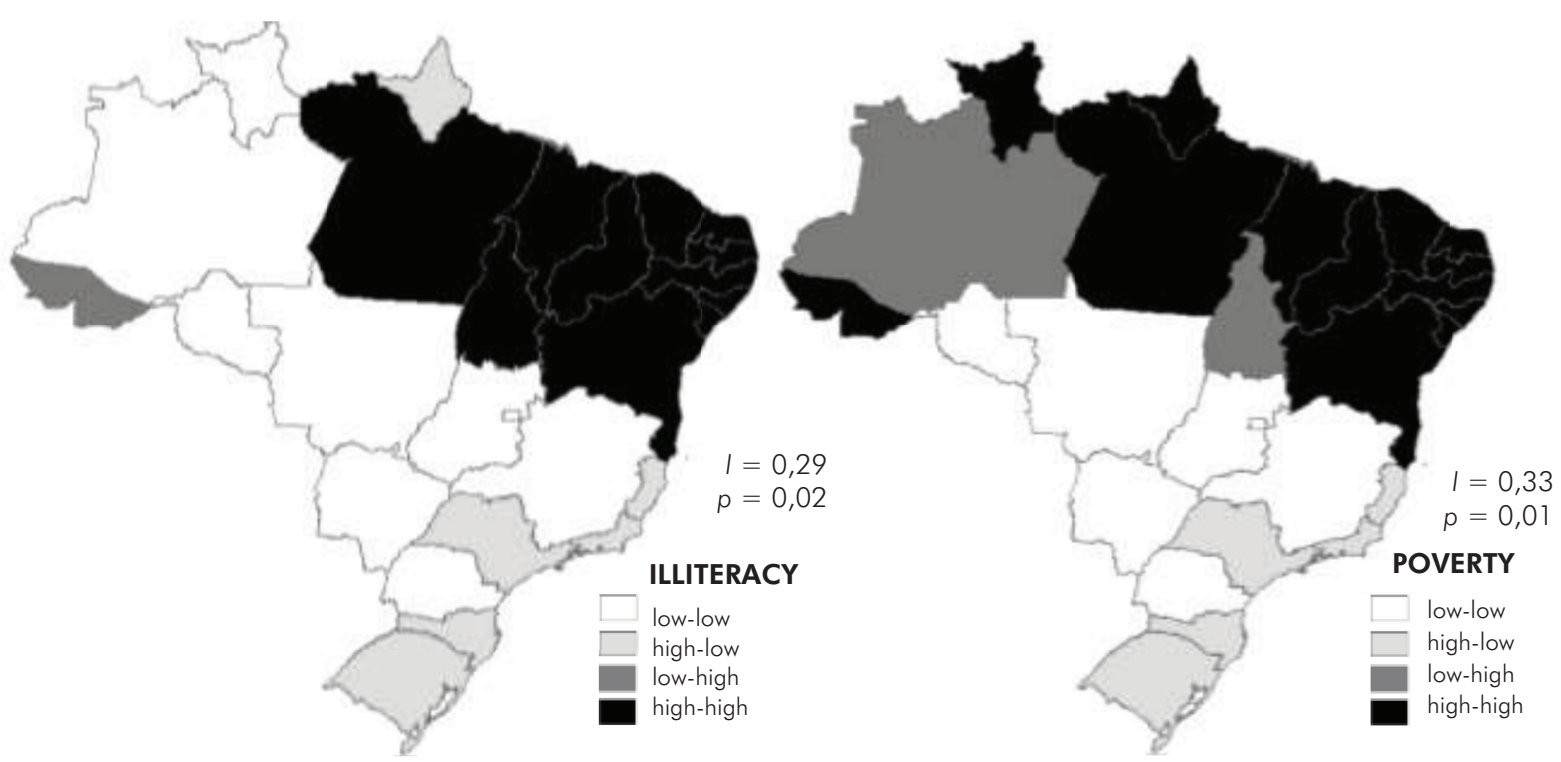

Figure 3. Box map of spatial distribution of Brazilian socioeconomic conditions showing illiteracy and poverty rates in 2009.

income would lead to a reduction of such index. Schooling rate also had negative spatial correlation, while illiteracy and poverty rates showed a positive spatial correlation with DMFT; poverty rate was the most highly correlated predictor of DMFT.

The bivariate spatial analysis (Figure 4) also indicated the formation of multiple clusters among states, such as clusters of low household per capita income and low rate of schooling correlated with high DMFT index in the northeast states, high rate of schooling correlated with low DMFT index in the center-south region, high illiteracy rate correlated with high DMFT index in the northeast states, as well as high poverty rate correlated spatially with high DMFT and low poverty rate with low DMFT in the southeastern and southern regions.

\section{Discussion}

The Brazilian population is going through a decrease in DMFT values, showing a consistent decreasing trend over the years, observed for the country as a whole and for the five regions, i.e., north, northeast, central-west, southeast, and south, indicating that all states influence the national decline of the indicator. ${ }^{9,10}$ The decline in the prevalence and severity of dental caries has also been reported in other American countries ${ }^{11}$ and represents a worldwide trend. ${ }^{12}$

Despite the evident progress in the decline of the DMFT index in recent years, the inequity in the distribution of the disease still remains, which can be explained by the difficult conditions to which most of the Brazilian population is subjected, establishing a true social apartheid. ${ }^{9}$

The spatial distribution of DMFT at 12 years of age in 2010 per federal states demonstrates a notorious social inequality and high variation among states, with the highest DMFT values in the northern and northeastern regions. ${ }^{910}$

Similarly, the analysis of socioeconomic characteristics of the population in the Brazilian states reveals a specific territorial pattern. In addition to the large interstate income differential that exist, there are other differentials not less important related to education level and the extent of poverty. As the results of this research show, all these economic indicators are related to oral health conditions of the population, i.e., people with the worst social conditions show the highest rates of DMFT in the northeast of Brazil.

The seaside-countryside contrast is in opposition to the very different north-south contrast, in which there are striking regional differences. However, 

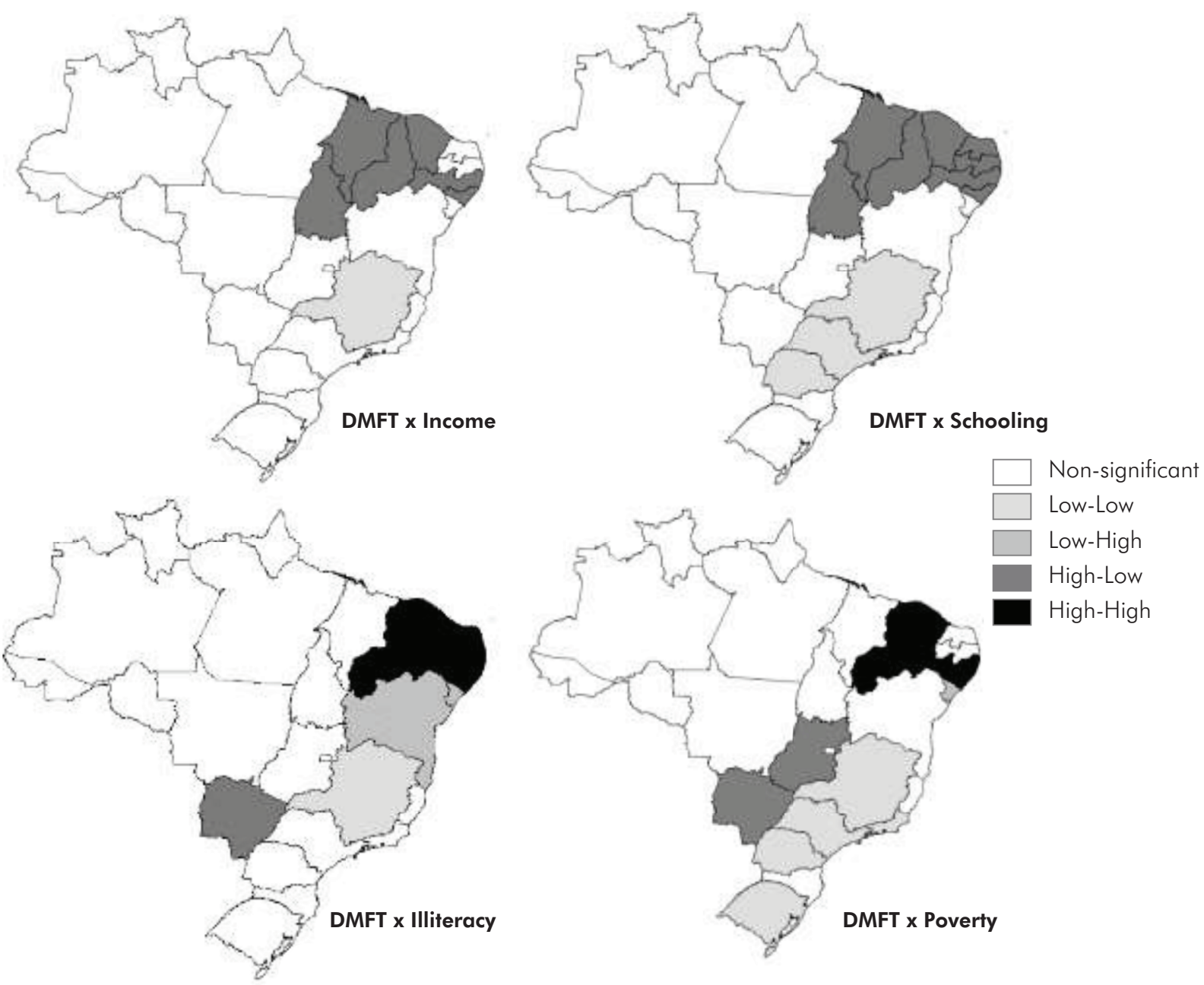

Figure 4. Moran's map of bivariate analyses between DMFT in 12-year-olds and socioeconomic conditions in 2009.

income concentration is a universal trend, occurring in Italy, France, and the United States. Once the phenomenon starts, its natural reversal is difficult. In Brazil, due to its territorial extension, such a process tends to increase. ${ }^{13}$

It is important to highlight the low socioeconomic conditions of the northern and northeastern populations of Brazil with high values of dental caries in the community. To better understand the vulnerability of these regions, it is necessary to know the political, social, and economic history of Brazil.

Poverty and the level of social inequality in Brazil are not due to insufficient resources, but to historical concentration processes. In Brazil, the poor population is higher in rural areas from the northeastern and northern areas of the country, decreasing towards the southern and mid-western regions, demonstrating a regional component of social inequality. ${ }^{13,14}$

The Brazilian economic development helps the understanding of the present situation. In the first half of the $20^{\text {th }}$ century, the economy comprised a system with minimal integration among regions. However, the growth of coffee production established regional income and provided the means for regions to articulate with one another. ${ }^{15}$

Although by mid-century the Brazilian economy advanced, the disparity among regional income levels increased noticeably. With the industrial development that followed the coffee success, the regional income concentration increased. ${ }^{14,15}$

The Brazilian industrialization process began simultaneously in almost all regions. The first textile 
industries were established in the northeast after the tax reform. However, capital accumulation took place in the southeastern region and the industrialization policy that had been implemented contributed to further expand regional inequalities. The crucial stage of income concentration occurred during World War I, when the industrial acceleration took place. . $^{13,14,15}$

National income data show the intensification of the wealth concentration during the post-war period. The participation of the state of São Paulo in the industrial production rose from 39.6 to $453 \%$ between 1948 and 1955. At the same time, the participation of the northeastern region declined from 163 to $9.6 \%$, establishing a growing disparity in per capita income among the regions of the country. ${ }^{16}$

According to Furtado, ${ }^{16}$ in 1955, São Paulo had a population of 10,330,000 inhabitants and industrial production 2.3 times greater than that of the northeast region with a population of 20,100,000 inhabitants. Per capita income in the region of São Paulo was, therefore, 4.7 times higher than that of the northeastern region. ${ }^{16}$

The differences between the standards of living in the different Brazilian regions - which are even higher today - gave rise to large political concerns. Studies on the subject support the adoption of measures for regional development. ${ }^{13,15,16}$

The awareness of economic interdependence among states in the first half of the $20^{\text {th }}$ century when regions related to one another around the coffee-industrial activity - raised the concern that the growth of a region might be counteracted by the stagnation of other regions. ${ }^{16}$

The current Brazilian situation reveals that the private sector got stronger with the internationalization of global conglomerates, financial liberalization, and productive restructuring within the axis of 'globalization'. As a consequence, social and regional inequalities grew, thus increasing the need to organize policies in order to reduce negative effects and reaffirm regional territorial cohesion. ${ }^{17}$

Social inequality is observed in the countryside of all regions of the country. This was shown in this study by the distribution of the Gini coefficient that did not show any spatial pattern in the Brazilian territory. Such inequalities are well clarified when the indicators concerning socioeconomic conditions are analyzed. In order to have an idea of the enormous imbalance of per capita income in Brazil in the 1990s, it is worth noting that Brasília had the highest annual per capita gross domestic product (GDP), which was five times larger than those of the states of Tocantins, Maranhão, Piauí, Ceará, and Rio Grande do Norte. ${ }^{18}$ In 2009, the GDP of São Paulo was 1,155,806,777 reals, while in Amapá, for example, it reached 7.654 .655 reals. ${ }^{4}$

The historical and cultural heritage of the northeastern region provides explanations for what is observed. When the work regime became wage-earning, low incomes predominated due to cultural backwardness, land ownership structure, and oligarchic dominance. This distinguishes the northeast as the region of retrogression and worrisome indicators that failed to provide alternatives to the semi-arid region to decrease the effects of climate adversity. ${ }^{19}$

Furtado $^{16}$ points out that the colonial period left important legacies for the social and economic development of Brazil. In particular, this inheritance is even more present in the northeast with the persistence of monoculture, the legacy of the 'sugar world', the technical backwardness and rudimental work, subsistence agriculture, disjointed and deepening poverty in the fields, and the patriarchal structure. ${ }^{16}$

This historical review aimed to explain the distribution of the caries disease in the national territory in a social, spatial, and temporal context. According to Milton Santos, the biological process of diseases must account for the economic, political, and cultural dimensions, factors that are responsible for disease development in a given population. ${ }^{20}$

The interaction between these social dimensions and health contributes to the development of specific interventions on communities, services, and other resources. Such interaction requires a cross-departmental government reflection on the general environment in which health, social, educational, economic, and judicial policies should be implemented. ${ }^{21}$

When the space is viewed as the location where diseases and harms to health occur, it is possible to observe that 'extraoral' factors, such as socioeconomic factors, can produce changes in the living conditions 
and health of the population..$^{22}$ Thus, an unequal socioeconomic development has consequences for the oral health in each part of the population. The $1986,{ }^{23} 2003,{ }^{24}$ and $2010^{25}$ SBBrasil epidemiological surveys showed that despite the general decline of caries indicators, the presence of discrepancy between regions is still considerably evident.

Individuals with higher levels of education have better oral health status, as higher education leads to an increased awareness about the importance of teeth and the needed care for oral health preservation, as well as more information about the disease and its prevention. Regional inequality has a direct influence on access to dental services, the profile of dental procedures, concentration of dentists, and other factors related to the DMFT. 26,27

Therefore, this study indicated the relationship between DMFT values of a population and the socioeconomic characteristics of its spatial location, which are historically determined.

\section{References}

1. Barros MBA. Social inequality in health: revisiting moments and trends in 50 years of publication of RSP. Rev Saúde Pública. 2017;51(17):1-8. https://doi.org/10.1590/s1518-8787.2017051000156

2. Brasil. Lei $N^{\circ} 8.080$, de 19 de setembro de 1990. Dispõe sobre as condições para promoção, proteção e recuperação da saúde, a organização e o funcionamento dos serviços correspondentes, e dá outras providências. Diário Oficial da União, 20 set. 1990.

3. Araújo AA, Morais GAS. [Income inequality and its decomposition in Brazil and in brazilian regions]. Rev Econ Nordeste. 2014 out-dez;45(4):35-51. Portuguese.

4. Instituto de Pesquisa Econômica Aplicada - IPEA. Rio de Janeiro: IPEA, 2018. [cited 2018 jul 18] Available from: http://www.ipeadata.gov.br

5. Jornada B, Santos BZ, Garcia LP, Dalpian DM, Backes DS, Krause LF. [Access and use of dental services among adolescents and associated factors in Brazil]. Disciplinarium Sci. 2016;13(2):275-88. Portuguese.

6. Silva JM, Penha E. [Access to services and dental tooth loss in children]. Rev Rede Cuidados Saúde. 2015;9(1):1-11. Portuguese.

7. Nunes BP, Flores TR, Garcia LP, Chiavegatto AD, Thumé E, Facchini LA, et al. [Time trend of lack of access to health services in Brazil, 1998-2013]. Epidemiol Serv Saude. 2016 Oct-Dec;25(4):777-87. Portuguese. https://doi.org/10.5123/S1679-49742016000400011

8. Roncalli AG, Projeto SB. [The SB Brasil 2010 Project: a key strategy for developing an oral health surveillance model]. Cad Saúde Pública. 2010;26(3):428-9. Portuguese. https://doi.org/10.1590/S0102-311X2010000300001

9. Agnelli PB. [Variation of brazilian CPOD index during the 1980 to 2010 period]. Rev Bras Odontol. 2016;72(1/2):10-5. Portuguese. https://doi.org/10.18363/rbo.v72i1/2.54910. Mendes HJ, Matos PE, Magalhães JR. [Dental caries and socioeconomic inequalities in Brazil]. Rev Saúde Com. 2016;12(1):454-62. Portuguese.

10. Gimenez T, Bispo BA, Souza DP, Viganó ME, Wanderley MT, Mendes FM, et al. Does the decline in caries prevalence of Latin American and Caribbean children continue in the new century? Evidence from systematic review with meta-analysis. PLoS One. 2016 Oct;11(10):e0164903. https://doi.org/10.1371/journal.pone.0164903

11. Kassebaum NJ, Bernabé E, Dahiya M, Bhandari B, Murray CJ, Marcenes W. Global burden of untreated caries: a systematic review and metaregression. J Dent Res. 2015 May;94(5):650-8. https://doi.org/10.1177/0022034515573272

12. Medeiros M, Souza PH, Castro FA. The stability of income inequality in Brazil, 2006-2012: an estimate using income tax data and household surveys. Cienc Saúde Coletiva. 2015;20(4):971-86. https://doi.org/10.1590/1413-81232015204.00362014

13. Prado JR. História econômica do Brasil. São Paulo: Brasiliense; 2012. 365 pp.

14. Almeida GG, Engel V. [The influence of the coffee economy the process of industrialization in Brazil old republic]. Rev Desenv Econ. 2016;2(34):581-92. Portuguese. https://doi.org/10.21452/rde.v2i34.4124

15. Furtado C. Formação econômica do Brasil. São Paulo: Companhia Editora Nacional; 2005.

16. Viana ALA, Ferreira MP, Cutrim MA, Fusaro ER, Souza MR, Mourão L, E† al. The regionalization process in Brazil: influence on policy, structure and organization dimensions. Rev Bras Saude Mater Infant. 2017;17(Suppl 1): S27-43. https://doi.org/10.1590/1806-9304201700s100003

17. Lavinas L, Garcia MH, Amaral MR. Desigualdades regionais e retomada do crescimento num quadro de integração econômica. Rio de Janeiro: Instituto de Pesquisa Econômica Aplicada/ 1997. (Texto para discussão, Vol. 466).

18. Massuquetti A, Franco MC Junior. O sul e o nordeste no Brasil: uma análise das diferenças no desenvolvimento sócio-econômico destas regiões. In: Aais do $2^{\circ}$ Encontro de Economia Catarinense, 2008 Apr 24-26, Chapecó, SC, Brazil.

19. Faria RM, Bortolozzi A. [Territory and healthin Milton Santos geography: theory and method for territorial planning the Unique Health System in Brazil]. Ra'e Ga. 2016;38:291-320. Portuguese. https://doi.org/10.5380/raega.v38i0.43912 
20. Bellis MA, Jarman I, Downing J, Perkins C, Beynon C, Hughes K, et al. Using clustering techniques to identify localities with multiple health and social needs. Health Place. 2012 Mar;18(2):138-43. https://doi.org/10.1016/i.healthplace.2011.08.003

21. Guarnizo-Herreño CC, Watt RG, Stafford M, Sheiham A, Tsakos G. Do welfare regimes matter for oral health? A multilevel analysis of European countries. Health Place. 2017 Jul;46:65-72. https://doi.org/10.1016/i.healthplace.2017.05.004

22. Ministério da Saúde (BR). Divisão Nacional de Saúde Bucal. Levantamento epidemiológico em saúde bucal: Brasil, zona urbana. Brasília, FDF: Ministério da Saúde; 1988.

23. Ministério da Saúde (BR). Departamento de Atenção Básica. Projeto SB Brasil 2003: condições de saúde bucal da população brasileira, 2002-2003: resultados principais. Brasília: Ministério da Saúde; 2004.

24. Ministério da Saúde (BR). Secretaria de Atenção à Saúde. Secretaria de Vigilância em Saúde. SB Brasil 2010: Pesquisa nacional de saúde bucal: resultados principais. Brasília: Ministério da Saúde; 2012.

25. Souza JG, Sampaio AA, Costa Oliveira BE, Jones KM, Martins AM. Socioeconomic inequalities in the use of dental care services during early childhood: an epidemiological survey. Int J Paediatr Dent. 2018 Jul;28(4):400-9. https://doi.org/10.1111/ipd.12368

26. Rocha NB, Garbin CA, Garbin AJ, Saliba O, Moimaz SA. Longitudinal study into the determining factors of dental caries in children aged 4: socio-behavioral aspects and oral health of pregnant women. Rev Gaucha Odontol. 2017;65(1):52-61. https://doi.org/10.1590/1981-863720170001000083221 